\title{
Analysis of the Effect of Musical Stimulation on Cortical Auditory Evoked Potentials
}

\author{
Daiane Damaris Baptista de Lima ${ }^{1}$ Simone Fiuza Regaçone ${ }^{2}$ Anna Caroline Silva de Oliveira ${ }^{1}$ \\ Yara Bagali Alcântara ${ }^{1}$ Eduardo Federighi Baisi Chagas ${ }^{3}$ Ana Claudia Figueiredo Frizzo ${ }^{1}$
}
1 Department of Speech Therapy and Audiology, Faculty of Philosophy and Science, Universidade Estadual Paulista, (FFC/UNESP), Marília (SP), Brazil
2 Department of Speech Therapy and Audiology, Dentistry School of Bauru, Universidade de São Paulo (FOB/USP), Bauru (SP), Brazil
3 Postgraduate Program in Human Development and Technology, Faculty of Philosophy, Sciences and Letters of Rio Claro, Universidade Estadual Paulista, Rio Claro, SP, Brazil; Department of Physical Education, Universidade de Marília, SP, Brazil

Address for correspondence Simone Fiuza Regaçone, Department of Speech Therapy and Audiology, Dentistry School of Bauru, Universidade de São Paulo (FOB/USP), Alameda Octávio Pinheiro Brisola, 9-75, Bauru - SP, 17012-901, Brazil (e-mail: simoneregacone@gmail.com).

Int Arch Otorhinolaryngol 2019;23:31-35.

\begin{abstract}
Keywords

- electrophysiology

- music

Introduction Cortical auditory evoked potentials (CAEPs) are bioelectric responses that occur from acoustic stimulations, and they assess the functionality of the central auditory system.

Objective The objective of the present study was to analyze the effect of musical stimulation on CAEPs.

Methods The sample consisted of 42 healthy female subjects, aged between 18 and 24 years, divided into two groups - G1: without musical stimulation prior to the CAEP examination; and G2: with stimulation prior to the examination. In both groups, as a pre-collection procedure, the complete basic audiological evaluation was performed. For the musical stimulation performed in G2, we used an MP4 player programmed to play Pachelbel's "Canon in D Major" for five minutes prior to the CAEP examination. To analyze the effect on the groups, the ear side and the ide-group interaction , a mixed analysis of variance (ANOVA) of repeated measures was performed. Box M test and Mauchly sphericity test were also performed.

Results Test differences were considered statistically significant when the p-value was $<0.05(5 \%)$. Thus, it was possible to observe that there was a statistically significant difference of the P2 component characterized by the decrease in the amplitude of response in the left ear in $\mathrm{G} 2$ when comparing the responses of CAEP with and without prior musical stimulation.

- auditory evoked potentials

Conclusion The result of the present study enabled us to conclude that there was a change in the response of CAEPs with musical stimulation.
\end{abstract}

\section{Introduction}

Cortical auditory evoked potentials (CAEPs) tests are neural bioelectrical responses that occur from acoustic stimulations, and they evaluate the functionality of the central auditory system. These potentials are characterized by the components $\mathrm{P} 1, \mathrm{~N} 1, \mathrm{P} 2, \mathrm{~N} 2$ and P3a, which are related to the perception and recognition of the acoustic and temporal characteristics of the auditory stimulus and represent a passive and automatic preattentional response of the auditory system. ${ }^{1,2}$ received

September 4, 2017

accepted

March 11, 2018

published online

July 25, 2018
DOI https://doi.org/

10.1055/s-0038-1651507. ISSN $1809-9777$.
Copyright $(2019$ by Thieme Revinter

Publicações Ltda, Rio de Janeiro, Brazil
License terms

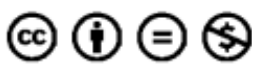


Studies on perception based on behavioral and neural information state that sensory systems are able to unconsciously analyze the characteristics of the stimuli and to differentiate deviant characteristics across stimuli. ${ }^{3}$ Auditory perception occurs through the activation of the reticular formation, the lemniscus, the inferior colliculus, the thalamus and the primary, frontal, central-parietal, temporal and supratemporal cortexes, which are neural structures involved in the CAEP response. ${ }^{2}$

Specifically, the response of the $\mathrm{P} 2$ component is linked to the discrimination of the acoustic characteristics of the stimulus. P2 amplitude is greater in people who have contact with music or specific musical training due to the sophistication of the perception of the acoustic characteristics. ${ }^{4-6}$

Many scientists are focused on researches that seek to highlight the advantages and benefits of auditory pathway stimulation with musical stimuli associated with auditory training. ${ }^{7-9}$

Recent studies report that there is a possibility of combining harmonious, rhythmic and melodic stimuli to positively influence the modulation of brain activity, which can be measured by CAEPs. ${ }^{10,11}$

Examining the Brazilian literature, we found a study that sought to understand the action of the various musical types and their velocities during the capture of auditory evoked potentials (AEPs) through cognitive tasks in healthy women. According to this study, the stimulus velocity did not influence the values of the AEP components. However, prior musical stimulation was a facilitating agent for the test, since the participants showed better attention during its performance. ${ }^{12}$

The objective of the present study was to understand the effects of prior musical stimulation on CAEPs, since they remain imprecise. In this sense, the knowledge of the action of musical stimuli on the central auditory cortex is extremely important for the development of our evaluation and treatment proposals.

Thus, the present study aimed to analyze the effect of musical stimulation on CAEPs.

\section{Method}

This is a cross-sectional study with a quantitative outlining, of analytical type, performed with the approval of the Research Ethics Committee of one of our institutions, under number 419/2012.

The study consisted of 42 healthy female subjects aged between 18 and 24 years. The sample was divided into two groups of 21 participants each: group 1 (G1), with the examination of CAEPs without prior musical stimulation; and group 2 (G2), with the examination of CAEPs with musical stimulation prior to the examination.

The exclusion criteria for the composition of the sample were: external and/or middle ear alterations, hearing loss and neurological disorders. The following pre-collection procedures were performed to evaluate auditory thresholds: audiological anamnesis, immittance audiometry and pure tone audiometry (air conduction headphones and a bone conduction vibrator were used).

The normal parameters considered in the auditory evaluations were: pure tone audiometry in the frequencies between 250 and $8,000 \mathrm{~Hz}$ with air conduction headphones and between 500 and $4,000 \mathrm{~Hz}$ with the bone conduction vibrator (with thresholds of $\leq 25 \mathrm{~dB}$ with air conduction and $\leq 15 \mathrm{~dB}$ with bone conduction), immittance audiometry with type A curve tympanogram, indicating normal mobility of the tympano-ossicular system and presence of ipsi and contralateral reflexes. ${ }^{13,14}$

Data collection was performed in a quiet and electricallyprotected room, at a temperature between 21 and $25^{\circ} \mathrm{C}$ and humidity between 50 and $60 \%$. During the CAEP tests for G1 and G2, the participants were instructed to remain alert by watching a video (without sound) to distract themselves and not direct their attention to the sound stimulus that was presented in an oddball paradigm (a rare stimulus randomly presented to the standard stimulus). The task performed during this examination was passive listening of the sound.

For CAEP acquisition, the Bio-logic Auditory Evoked Potential (AEP) software (Natus Medical Incorporated, Pleasanton, CA, US) was used, with five disposable electrodes positioned at $\mathrm{Fz}$ and $\mathrm{Cz}$ in reference to the right lobe (A2) and left lobe (A1) alternately and ground at Fpz, using the 2 recording channels of the equipment and the following parameters: filter between 0.5 and $30 \mathrm{~Hz}$, monaural stimulation (burst tones with $10-\mathrm{ms}$ plateau and $5-\mathrm{ms}$ rise/fall), with a frequency of $750 \mathrm{~Hz}$ for the standard stimulus and $1,000 \mathrm{~Hz}$ for rare stimulus, with a $20 \%$ probability, interval between stimuli of $1.1 \mathrm{~ms}$, intensity of $70 \mathrm{~dB} \mathrm{NA}$, analysis time of $500 \mathrm{~ms}$, amplification of $100 \mathrm{x}$, alternating polarity, and number of samples of 200 stimuli. $^{13}$

For the final analysis of the results, the records obtained at $\mathrm{Cz}$ were used, because in this region the records had better wave morphology when compared to the records obtained in Fz.

The latencies and amplitudes of the N1, P2 and N2 waves were marked following the appearance of the first three waves, in the highest peak, sequentially, in the negativepositive-negative polarities respectively, between 60 and $300 \mathrm{~ms}$, in relation to tracing replication. ${ }^{15}$ As for the P3a component, its latency was marked between 220 and 350 ms. ${ }^{16}$ The P3b component was not analyzed in the present study. The P3a is one of the components of CAEP related to the processes of early warning and auditory sensory processing, which occurs automatically in response to the perception of the stimulus difference, regardless of the individual's active attention to the stimulus sequence. ${ }^{17}$

For the musical stimulation performed in G2, an MP4 player was used, which was programmed to play Pachelbel's "Canon in D Major", with an intensity between 60 and $80 \mathrm{~dB}$ for 5 minutes prior to CAEP testing.

The tests lasted $\sim 50$ minutes for both groups. As a standard to maintain a quality examination, for the volunteers who presented myogenic interference, positional changes were suggested, and the examination was repeated when necessary.

Data were described through mean and standard deviation (SD). The normality distribution was verified through the Kolmogorov-Smirnov test, and the homogeneity through the Levene test. Mixed Anova of repeated measures was used to analyze the effect on the groups, the ear side and the 
side-group interaction. The Box $M$ test was used to verify whether the covariance matrices of the observed dependent variables were the same for both groups, and the Mauchly sphericity test was used to test the sphericity hypothesis. In the case of rejection of the sphericity hypothesis, the analyses were based on the Greenhouse-Geisser multivariate test. Peer-to-peer comparisons were performed using the Bonferroni Post-Hoc test. The level of significance was set at $p<0.05$.

\section{Results}

Considering that there may be differences between the left and right sides, - Table 1 explored the relationship between the groups and the ear side. In G1, a significant difference was observed between the left and right sides for the amplitude values (P2 AMP), but between G1 and G2, the difference in P2 AMP was observed only on the left side. Although there was no interaction observed between ear side and group for P2 AMP, the results suggest that the presence of music has a greater impact on the left side, because the difference between the left and right sides ceases to exist in the presence of music. - Fig. 1 presents the mean and 95\% confidence intervals (95\%CIs) for P2 AMP values for G1 and G2 on the left and right sides.

\section{Discussion}

According to the data obtained in the comparison between G1 and G2, there was a decrease in the amplitude of the P2 component in the left ear after the musical stimulation.

The P2 component is a marker component of auditory discrimination and correlated processes related to the

Table 1 Comparison of cortical auditory evoked potential measurements between G1 and G2 for the right and left sides

\begin{tabular}{|c|c|c|c|c|c|c|c|}
\hline \multirow[b]{2}{*}{ Variable } & \multirow[b]{2}{*}{ Group } & \multicolumn{2}{|c|}{ Left Side } & \multicolumn{2}{|c|}{ Right Side } & \multirow{2}{*}{$\begin{array}{l}\text { Side } \\
p\end{array}$} & \multirow{2}{*}{$\begin{array}{l}\text { Side-group } \\
\text { interaction }\end{array}$} \\
\hline & & Mean & SD & Mean & SD & & \\
\hline \multirow[t]{2}{*}{ LATN1 } & G1 & 97.6 & 13.7 & 98.3 & 9.7 & 0.836 & \multirow[t]{3}{*}{0.667} \\
\hline & G2 & 102.4 & 17.1 & 101.0 & 16.9 & 0.689 & \\
\hline Group & $P$ & \multicolumn{2}{|l|}{0.315} & \multicolumn{2}{|l|}{0.534} & & \\
\hline \multirow[t]{2}{*}{ N1AMP } & G1 & -4.7 & 1.8 & -4.8 & 1.8 & 0.784 & \multirow[t]{3}{*}{0.308} \\
\hline & G2 & -4.2 & 1.9 & -4.8 & 1.8 & 0.090 & \\
\hline Group & $P$ & \multicolumn{2}{|l|}{0.387} & \multicolumn{2}{|l|}{0.971} & & \\
\hline \multirow[t]{2}{*}{ P2LAT } & G1 & 175.4 & 26.7 & 169.9 & 29.8 & 0.357 & \multirow[t]{3}{*}{0.795} \\
\hline & G2 & 177.7 & 35.0 & 170.0 & 29.9 & 0.201 & \\
\hline Group & $P$ & \multicolumn{2}{|l|}{0.818} & \multicolumn{2}{|l|}{0.996} & & \\
\hline \multirow[t]{2}{*}{ P2AMP } & G1 & 2.9 & 2.1 & 2.2 & 2.0 & $0.026^{*}$ & \multirow[t]{3}{*}{0.098} \\
\hline & G2 & 1.7 & 1.7 & 1.7 & 1.7 & 0.929 & \\
\hline Group & $P$ & \multicolumn{2}{|l|}{$0.043^{*}$} & \multicolumn{2}{|l|}{0.352} & & \\
\hline \multirow[t]{2}{*}{ N2LAT } & G1 & 227.4 & 35.6 & 221.6 & 37.8 & 0.545 & \multirow[t]{3}{*}{0.856} \\
\hline & G2 & 228.5 & 48.0 & 220.3 & 35.5 & 0.390 & \\
\hline Group & $P$ & \multicolumn{2}{|l|}{0.931} & \multicolumn{2}{|l|}{0.910} & & \\
\hline \multirow[t]{2}{*}{ N2AMP } & G1 & -1.3 & 1.2 & -1.8 & 2.0 & 0.229 & \multirow[t]{3}{*}{0.968} \\
\hline & G2 & -1.6 & 1.3 & -2.1 & 1.6 & 0.208 & \\
\hline Group & $P$ & \multicolumn{2}{|l|}{0.439} & \multicolumn{2}{|l|}{0.571} & & \\
\hline \multirow[t]{2}{*}{ P3LAT } & G1 & 282.1 & 32.2 & 289.0 & 32.5 & 0.451 & 0.850 \\
\hline & G2 & 295.1 & 49.4 & 299.6 & 45.6 & 0.626 & \\
\hline Group & $P$ & 0.317 & & 0.393 & & & \\
\hline P3AMP & G1 & 1.9 & 2.2 & 2.0 & 1.8 & 0.787 & 0.772 \\
\hline & G2 & 2.1 & 1.4 & 2.4 & 1.0 & 0.498 & \\
\hline Group & $P$ & 0.773 & & 0.441 & & & \\
\hline N2 P3AMP & G1 & -3.3 & 2.7 & -3.7 & 3.5 & 0.500 & 0.584 \\
\hline & G2 & -3.7 & 2.3 & -4.5 & 1.9 & 0.152 & \\
\hline Group & $P$ & 0.607 & & 0.335 & & & \\
\hline
\end{tabular}

Abbreviations: AMP, amplitude; G1,group 1, without music; G2, group 2, with music; LAT, latency; SD, standard deviation.

Note: ${ }^{*} p \leq 0.05$ for the Bonferroni Post-Hoc test. 


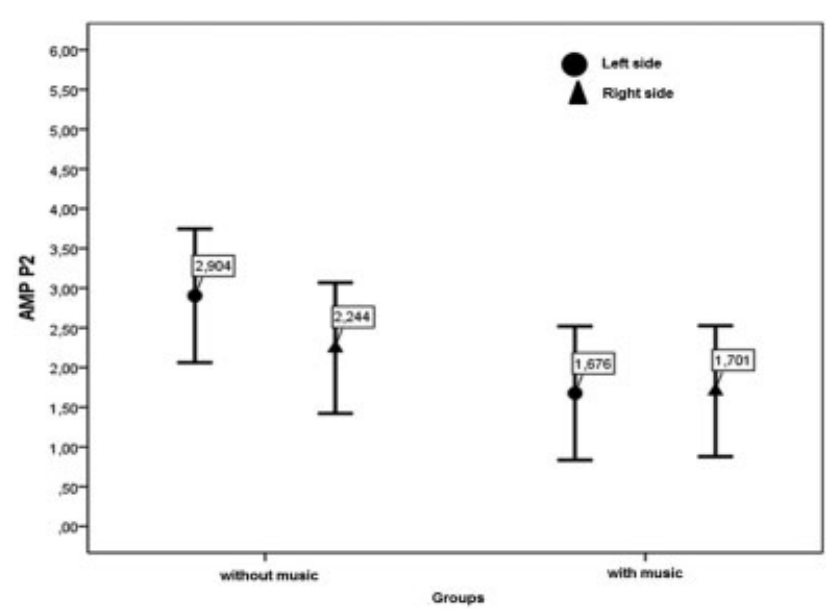

Fig. 1 Mean and 95\% confidence intervals (95\% Cl) for P2 AMP values for groups without and with music on the left and right sides.

perception of distinct acoustic characteristics among the stimuli. ${ }^{18}$ Musical assimilation is linked to this component due to the fact that the source is the superior temporal cortex, more specifically the primary auditory cortex, which is responsible for the perception of duration, intensity and timbre. ${ }^{1,2,19,20}$

The amplitude of the P2 wave corresponds to the volume of electrical activity that travels during the processing of the acoustic characteristics in the cortex, and is formed according to the level of concentration of the subject. Musical stimulation may have produced increased levels of alertness and concentration among the subjects in the responses to the musical stimulus. And consequently, a decrease in the preattentional automatic hearing responses may be related to the auditory discrimination of the auditory stimulus used in testing the CAEP.

In the other components of the CAEP (N1, N2 and P3a), no effect of musical stimulation was observed, possibly because the auditory components originate from distinct neural generators and assume different functions in the auditory response processing. The $\mathrm{N} 1$ reflects the detection of characteristics and acoustic changes; the N2 is a mixed component, for it reflects the physical discrimination of the acoustic characteristics of the stimulus and is related to the passive and automatic pre-attentional response that precedes the stimulus; and the P3a reflects an alert process when involuntary attention is redirected to unexpected events resulting from the detection of the deviant stimulus. $1,2,17,19$

The results showed significant differences between the ears. Following a structural model, we can explain that the auditory information of the left ear is processed in the right hemisphere, concerning the non-verbal characteristics related to music and to tonal stimuli used in CAEP testing. Such an explanation justifies the difference in amplitude in the opposite hemisphere in both groups. ${ }^{21,22}$

In addition, the automatic response of the processing of acoustic stimuli and the involuntary perception of the presence of one stimulus among others can suffer the effects of a conditioning of the response and loss of "attention."23,24
Such behavior is consistent with a decrease in the amplitudes of the CAEP components, especially the P2, generated by the depolarization of a group of neurons in specific regions of the brain. ${ }^{25}$

Greater control of the duration of the stimuli, separated by short intervals, can insure more reliable measures and enable the investigation of this behavior in future studies.

In addition, some studies relate attentional abilities with characteristics related to the rhythm of the auditory stimulus during musical listening. ${ }^{26}$ Recently, a study showed that there was a significant correlation between the auditory and cortical systems when simple acoustic stimuli were presented, and, therefore, corroborated our study. ${ }^{6}$

\section{Conclusion}

The result of the present study allowed us to conclude that there was a change in the CAEPs response with prior musical stimulation in the female population.

\section{Note}

The research was performed at Center for Education and Health Studies, Department of Speech Therapy and Audiology, Faculty of Philosophy and Science, Universidade Estadual Paulista “Júlio de Mesquita Filho" (Unesp), in the city of Marília (SP), Brazil.

The paper was presented at the 30th International Meeting in Audiology, held in the city of Bauru (SP), between April 8th and 11th, 2015.

\section{Conflict of Interests}

The authors declare that there is no conflict of interests in relation to the publication of this article.

\section{Acknowledgments}

We would like to thank Fundação de Amparo à Pesquisa do Estado de São Paulo (Fapesp) for the support granted to perform this research, under process number 2012/13149-0.

\section{References}

1 McPherson DL. Late potentials of the auditory system. San Diego: Singular Publishing Group; 1996

2 J. H. Handbook of auditory evoked responses. Boston: Allyn \& Bacon; 2006

3 Fiser J, Berkes P, Orbán G, Lengyel M. Statistically optimal perception and learning: from behavior to neural representations. Trends Cogn Sci 2010;14(03):119-130

4 Habibi A, Cahn BR, Damasio A, Damasio H. Neural correlates of accelerated auditory processing in children engaged in music training. Dev Cogn Neurosci 2016;21:1-14

5 Emerson S, Daltrozzo J, Conway C. The Effect of Music Experience on Auditory Sequential Learning: An ERP Study. Proc Cogn Sci Soc. 2014;36(36):xx

6 Shahin A, Roberts LE, Pantev C, Trainor LJ, Ross B. Modulation of P2 auditory-evoked responses by the spectral complexity of musical sounds. Neuroreport 2005;16(16):1781-1785

7 Looi V, Gfeller K, Driscoll V. Music Appreciation and Training for Cochlear Implant Recipients: A Review. Semin Hear 2012;33(04): 307-334 
8 Hutter E, Argstatter H, Grapp M, Plinkert PK. Music therapy as specific and complementary training for adults after cochlear implantation: A pilot study. Cochlear Implants Int 2015;16 (Suppl 3):S13-S21

9 Liang C, Earl B, Thompson I, et al. Musicians Are Better than Nonmusicians in Frequency Change Detection: Behavioral and Electrophysiological Evidence. Front Neurosci 2016;10:464

10 Sturm I, Dähne S, Blankertz B, Curio G. Multi-Variate EEG Analysis as a Novel Tool to Examine Brain Responses to Naturalistic Music Stimuli. PLoS One 2015;10(10):e0141281

11 Ross B, Fujioka T. 40-Hz oscillations underlying perceptual binding in young and older adults. Psychophysiology 2016;53(07):974-990

12 Sá CI, Pereira LD. Musical rhythms and their influence on P300 velocity in young females. Rev Bras Otorrinolaringol (Engl Ed) 2011;77(02):158-162

13 Jerger J. Clinical experience with impedance audiometry. Arch Otolaryngol 1970;92(04):311-324

14 Lloyd LL, Kaplan H. Audiometric Interpretation: a manual of basic audiometry. Baltimore: University Park Press; 1978

15 Junqueira CAO, Colafêmina JF. Investigação da estabilidade inter e intra-examinador na identificação do P300 auditivo: análise de erros. Rev Bras Otorrinolaringol 2002;68(04):468-478

16 Polich J, Howard L, Starr A. Effects of age on the P300 component of the event-related potential from auditory stimuli: peak definition, variation, and measurement. J Gerontol 1985;40(06): 721-726

17 Seppänen M, Pesonen AK, Tervaniemi M. Music training enhances the rapid plasticity of $\mathrm{P} 3 \mathrm{a} / \mathrm{P} 3 \mathrm{~b}$ event-related brain potentials for unattended and attended target sounds. Atten Percept Psychophys 2012;74(03):600-612

18 Tremblay KL, Ross B, Inoue K, McClannahan K, Collet G. Is the auditory evoked P2 response a biomarker of learning? Front Syst Neurosci 2014;8:28

19 Naatanen RPT. N2 and Automatic versus Controlled Processes. In: Mccallum WC, Zappoli RDF, editor. Cerebral psychophysiology: Studies in event-related potentials. New York: Elsevier; 1986: 169-186

20 Stewart L, von Kriegstein K, Warren JD, Griffiths TD. Music and the brain: disorders of musical listening. Brain 2006;129(Pt 10): 2533-2553

21 Luria AR. Higher cortical functions in man. Basic Books; 1980:634

22 O'Brien JL, Nikjeh DA, Lister JJ. Interaction of Musicianship and Aging: A Comparison of Cortical Auditory Evoked Potentials. Behav Neurol 2015;2015:545917

23 Pandey AK, Kamarajan C, Tang Y, et al. Neurocognitive deficits in male alcoholics: an ERP/sLORETA analysis of the N2 component in an equal probability Go/NoGo task. Biol Psychol 2012;89(01): 170-182

24 Aron AR, Robbins TW, Poldrack RA. Inhibition and the right inferior frontal cortex: one decade on. Trends Cogn Sci 2014;18 (04):177-185

25 Kok A. Event-related-potential(ERP) reflections of mental resources: a review and synthesis. Biol Psychol 1997:45(1-3):19-56

26 Fitzroy AB, Sanders LD. Musical Meter Modulates the Allocation of Attention across Time. J Cogn Neurosci 2015;27(12): 2339-2351 